SHORT REPORT

\title{
Relative high frequency of the c.255delA parkin gene mutation in Spanish patients with autosomal recessive parkinsonism
}

\author{
E Muñoz, E Tolosa, P Pastor, M J Martí, F Valldeoriola, J Campdelacreu, R Oliva
}

J Neurol Neurosurg Psychiatry 2002;73:582-584

Background: Autosomal recessive juvenile parkinsonism is a neurodegenerative disorder associated with mutations in the parkin gene.

Objectives: To search for the presence of parkin gene mutations in Spanish patients with Parkinson's disease (PD) and characterise the phenotype associated with these mutations.

Methods: Thirty seven PD patients with either early onset or autosomal recessive pattern of inheritance were selected for genetic study.

Results: Mutations were identified in seven index patients (19\%). Homozygous mutations were detected in six patients and a heterozygous mutation in one. The age at onset was lower in patients with mutations than in patients without mutations. Dystonia at onset was present in two patients with parkin gene mutations. The disease began in two patients with postural tremor in the upper limbs mimicking essential tremor. Four patients exhibited a long term response to dopamine agonists. The c. 255 delA mutation was identified in four unrelated families. This is a frameshift mutation leading to protein truncation.

Conclusions: Parkin gene mutations are present in Spanish patients with early onset and/or an autosomal recessive parkinsonism. The c. $255 \mathrm{del} A$ is the most frequent mutation found, suggesting a relative high prevalence in the Spanish population.

$\mathrm{P}$ atients with parkinsonism associated with parkin gene mutations usually present an autosomal recessive pattern of inheritance and have early onset disease, with a mean age at onset of around 30 years. The disease is also characterised by symmetrical involvement, slow progression, foot dystonia at onset, hyperreflexia, good response to levodopa therapy, and early levodopa induced dyskinesias. ${ }^{12}$ However, unusual features such as late onset disease, ${ }^{34}$ which can begin at an age similar to that of typical Parkinson's disease (PD), a rapidly progressive course, ${ }^{5}$ or the presence of gait ataxia ${ }^{6}$ have been described in patients with parkin gene mutations.

Many parkin gene mutations (exonic deletions and multiplications, and point mutations) have been described in patients from different populations. ${ }^{2}$ We have searched for parkin gene mutations in our PD patients in order to identify new mutations and to define further the clinical spectrum associated with these mutations.

\section{MATERIALS AND METHODS}

\section{Subjects}

Patients fulfilling the clinical diagnostic criteria for PD proposed by the UK Parkinson's Disease Society Brain Bank, except for the exclusion criteria of familial disorder, ${ }^{7}$ were recruited from the PD Movement Disorder Unit of the Hospital Clinic of Barcelona. Control subjects were recruited among healthy donors without familial history of PD or tremor.

Parkinsonian patients with either age at onset $\leqslant 40$ years or an autosomal recessive pattern of inheritance were selected for genetic study. The study was approved by the ethics committee of our hospital.

\section{Genetic study}

DNA was isolated from patients' leucocytes by standard procedures. The different exons of the parkin gene were amplified by polymerase chain reaction (PCR) using primers and conditions as described. ${ }^{18}$ A single strand conformational polymorphism (SSCP) analysis of the PCR products was carried out through electrophoresis in two different conditions: $7.5 \%$ polyacrylamide gel at room temperature and $12 \%$ polyacrylamide gel at $4^{\circ} \mathrm{C}$. The bands were visualised after silver staining. PCR products with an abnormal motility pattern were sequenced. The normal cDNA sequence of parkin gene (DNA Data Bank of Japan: AB009973) was obtained from the GenBank database (http://www.ncbi.nlmnih.gov/Genbank).

\section{Statistical assessment}

Means were compared with the non-parametric MannWhitney $U$ test. Frequencies were compared with the $\chi^{2}$ test.

\section{RESULTS}

We identified 37 index patients ( 17 women, 20 men) fulfilling the criteria proposed for the screening of mutations in the parkin gene. Twenty four were familial PD cases, with other siblings affected, and 13 were sporadic early onset PD cases.

Parkin gene mutations were found in seven index patients (19\%; table). Six patients had homozygous mutations that consisted of two frameshift mutations (c.255delA found in four patients and c.972delG found in one patient) and one exon rearrangement (exon 5-6del). One patient had a heterozygous mutation (Val15Met). We sequenced the coding region of parkin gene in this patient and his brother, who also carried the mutation and was affected by the disease, but we did not find any other mutations. The Vall5Met mutation was not found in 120 chromosomes belonging to $30 \mathrm{PD}$ patients and 30 healthy control subjects, supporting the fact that this could be a new missense mutation. In addition to these mutations, we identified two polymorphisms in our patients. ${ }^{39}$ Val/Leu380 was found in two unrelated families with late onset parkinsonism and Asp/Asn394 in a patient with sporadic juvenile onset parkinsonism.

Abbreviations: PD, Parkinson's disease; PCR, polymerase chain reaction; SSCP, single strand conformational polymorphism; UPDRS, unified Parkinson's disease rating scale 
Table 1 Clinical features of patients with parkin gene mutations

\begin{tabular}{|c|c|c|c|c|c|c|c|c|c|c|c|}
\hline $\begin{array}{l}\text { Index } \\
\text { patient }\end{array}$ & $\begin{array}{l}\text { Mutation } \\
\text { (exon) }\end{array}$ & $\begin{array}{l}\text { Type of } \\
\text { mutation }\end{array}$ & $\begin{array}{l}\text { Familial } \\
\text { status }\end{array}$ & $\begin{array}{l}\text { Siblings } \\
\text { (affected)* }\end{array}$ & Gender & $\begin{array}{l}\text { Age at } \\
\text { onset }\end{array}$ & $\begin{array}{l}\text { Disease } \\
\text { duration }\end{array}$ & L-dopa & Dystonia & UPDRS† & $\mathrm{H}-\mathrm{Y} \ddagger$ \\
\hline PK-11 & 972delG (7) & F (Ala291 Leu) & Sporadic & 7 & Female & 20 & 18 & No & Yes & 9 & 1.5 \\
\hline PK-21 & 255 delA (2) & F (Asn52Met) & Familial & $6(1)$ & Male & 41 & 12 & Yes & No & 30 & 1.5 \\
\hline PK-131 & 255 delA (2) & $\mathrm{F}$ (Asn52Met) & Familial & $3(1)$ & Female & 34 & 9 & Yes & No & 36 & 2 \\
\hline PK-184 & 255 delA (2) & $\mathrm{F}$ (Asn52Met) & Familial & $4(1)$ & Female & 30 & 35 & No & Yes & 38 & 3 \\
\hline PK-196 & $144 G>A(2)$ & $M$ (Val15Met) & Familial & $6(1)$ & Male & 46 & 2 & No & No & 9 & 1 \\
\hline PK-201 & 255 delA (2) & $\mathrm{F}$ (Asn52Met) & Sporadic & 2 & Female & 32 & 8 & No & No & 16 & 1.5 \\
\hline PK-205 & Exon5-6del & Rearrangement & Familial & $3(1)$ & Female & 27 & 40 & Yes & No & 26 & 3 \\
\hline
\end{tabular}

$F$, frameshift; $M$, missense mutation.

*Siblings clinically affected by the disease; †Unified Parkinson's disease rating scale; $¥$ Hoehn and Yahr stage.

Two of seven patients with parkin gene mutations were sporadic cases. Six patients were Spanish and one came from Morocco (PK-11). The mean age at onset (SD) was 32.8 (8.6) years in patients with mutations and 44.4 (15) years in patients without mutations $(p=0.02)$. Dystonia was only found in two patients with parkin gene mutations. These patients developed the disease at the age of 20 and 30 years, respectively. All patients had a good response to levodopa and/or other dopamine agonists. The mean (SD) motor score of the unified Parkinson's disease rating scale (UPDRS) in the "on" stage was 23.4 (8.6). One of three patients (PK-205) treated with levodopa showed choreiform "on" dyskinesias.

\section{c.255delA mutation}

The c.255delA mutation was found in four unrelated patients. All patients but one were living in Barcelona but they were originally from different regions in Spain. Parents' consanguinity was confirmed only in one case (patient PK-21). The age at onset of the disease ranged from 30 to 41 years. All patients developed symmetrical parkisonian signs (tremor, rigidity, and bradykinesia); however, the clinical features at onset varied among the patients. Only one patient (PK-184) presented with feet dystonia at onset. This patient is now 65 years old and she is treated only with the dopamine agonist bromocriptine. Another patient (PK-21) was initially diagnosed to have essential tremor because for several years he only exhibited postural tremor on his hands that responded partially to propanolol. He is now treated with very low doses of levodopa and selegiline. The third patient (PK-131) began her disease with tremor in the upper limbs, which was present at rest but increased in frequency notably when she held the arms outstretched. The last patient (PK-201) presented with slow gait and short steps and had an excellent response to bromocriptine, trihexyphenidyl, and selegiline, eight years after disease onset.

The genetic study of siblings of patients PK-21 and PK-131 lead us to identify heterozygous and homozygous carriers of the mutation. One homozygous carrier (L97-516) was a 47 year old woman who was the sister of patient PK-21. She did not present parkinsonian signs at the time of examination. However, another homozygous carrier (L00-379), a 42 year old woman, who was the sister of patient PK-131 and had not previously been diagnosed with PD, showed bradykinesia and slight symmetrical rigidity on the extremities, associated with slight postural tremor on her hands. None of the heterozygous carriers of the mutation presented parkinsonian signs.

Both homozygous and heterozygous mutated alleles showed a clear and reproducible pattern of bands by SSCP that were different from those obtained for normal alleles (fig 1). Thus, we considered that SSCP was an easy method to investigate the presence of the c.255delA mutation in normal subjects in order to estimate the prevalence of this mutation in our population. Subsequently, we screened for the c. $255 \mathrm{del} A$ mutation in 100 healthy control subjects and found a single subject with an abnormal SSCP pattern suggesting the

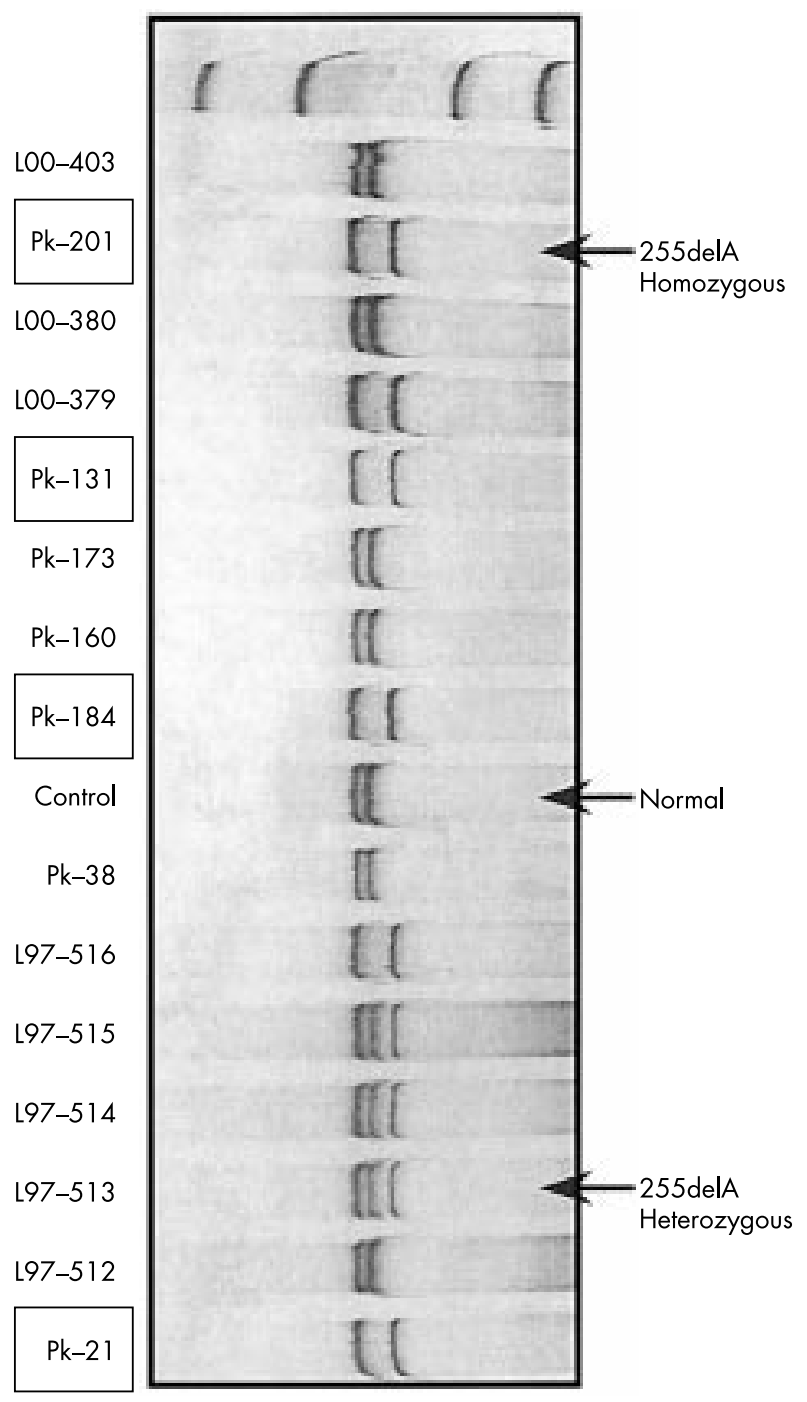

Figure 1 SSCP of exon 2 showing different patterns of motility in control subjects and homozygous and heterozygous carriers of the 255delA mutation.

presence of the mutation in heterozygosity. The mutation was confirmed after sequencing the PCR product. Application of the Hardy-Weinberg principle allowed us to calculate an approximate genetic risk of $1 / 40000$. We therefore estimate that about 1000 individuals could be homozygous carriers for the mutation in the Spanish population.

\section{DISCUSSION}

We found parkin gene mutations in two sporadic early onset $\mathrm{PD}$ cases and in five familial PD cases with an autosomal 
recessive pattern of inheritance. The clinical features of our patients lead us to confirm a phenotypic variability in patients with parkin gene mutations.

The age at onset of patients with mutations varied from 20 to 46 years. The mean age at onset was significantly lower in patients with parkin gene mutations than in those without mutations. Similar results have been previously reported by Lücking and colleagues. ${ }^{1}$ Only two of our patients presented with foot dystonia at onset. Dystonia has been reported in $42 \%$ of patients in a large series of patients with parkin gene mutations. ${ }^{2}$ The motor score of the UPDRS with the patients under the effect of medication ("on" situation) showed a mild to moderate parkinsonism. None of the four patients who were only taking dopamine agonists complained of dyskinesias. Two of them have been treated with dopamine agonists for over 15 years. This finding suggests that some patients with parkin gene mutations may respond successfully to dopamine agonists for a long period of time; also, the appearance of dyskinetic movements may be prevented.

The most relevant finding in our study was the presence of the same mutation (c.255delA) in four unrelated Spanish patients, suggesting that this mutation could be relatively frequent in our population. The presence of the mutation in 1 of 200 chromosomes from healthy controls supports this view. We have estimated that the frequency of homozygous carriers for the mutation could be $1 / 40000$ in Spain. Although we cannot rule out a random effect for our findings, other evidence supports the fact that c. 255 delA may be a frequent mutation in Europe. This mutation has been described previously in two Spanish patients and in five other European patients. $^{21011}$ Haplotype analysis of patients from differents countries carrying the mutation detected that the mutation segregates with allele 7 of marker D6S1599, ${ }^{11}$ which is located $24 \mathrm{~kb}$ downstream of exon 2. This finding suggests that the c. 255 delA mutation is possibly an ancestral European mutation.

The c.255delA is a frameshift mutation that leads to a change into the amino acid sequence starting at codon 52 (Asn52Met), and the appearance of a stop codon (TGA) at position 80 that truncates the parkin protein. The age at onset of the disease in patients carrying this mutation varies from 30 to 41 years in our series. However, we have found this mutation in a healthy 47 year old woman (PK-21 sister). Intrafamilial variability of the age at onset has been reported previously in a family from Italy with a deletion of exon 4. One member of this family developed the disease at the age of 58, whereas two siblings developed it at the ages of 38 and 41 , respectively. ${ }^{3}$ Interfamilial phenotype variability for the c. 255 delA mutation was also shown in our study. One patient had dystonia at onset; two presented with predominant postural tremor in the upper limbs, mimicking essential tremor; and another had a predominant lower body parkinsonism.

We are aware that some mutations could have been missed in our study because of the approach we have used to detect mutations. Although the sensitivity of the SSCP analysis performed using two different conditions is high, it is not
$100 \% .{ }^{12}{ }^{13}$ Moreover, heterozygous exon deletions or exon multiplications require a semiquantitative PCR for their detection. Unfortunately, this technique is not yet available in our laboratory. However, our work confirms the presence of parkin gene mutations in Spanish PD patients and contributes to the characterisation of the phenotype associated with these mutations. Moreover, it has allowed us to outline a relative high prevalence of the c.255delA mutation in our population. The clinical spectrum of parkin gene mutations remains open to discussion and further genetic and pathological studies are still needed to confirm our findings.

\section{Authors' affiliations}

E Muñoz, E Tolosa, P Pastor, M J Martí, F Valldeoriola,

J Campdelacreu, Movemente Disorder Unit, Neurology Service, Institut Clinic de Malalties del Sistema Nervios, Villarroel 170, 08036 Barcelona, Spain

R Oliva, Genetics Service, Centre de Diagnóstic Biomèdic, Institut de Investigacions Biomèdiques Agustí Pi i Sunyer (IDIBAPS). Hospital Clínic i Universitari, Barcelona, Spain

Competing interests: none declared

Correspondence to: Dr E Muñoz, Neurology Service, Hospital Clinic of Barcelona, Villarroel, 170, 08036 Barcelona, Spain; jemunoz@clinic.ub.es

Received 19 February 2002

In revised form 31 July 2002

Accepted 31 July 2002

\section{REFERENCES}

1 Kitada T, Asakawa S, Hattori N, et al. Mutations in the parkin gene cause autosomal recessive juvenile parkinsonism. Nature 1998;392:605-8

2 Lücking CB, Dürr $A$, Bonifati $V$, et al. Association between early-onset Parkinson's disease and mutations in the parkin gene. N Engl J Med 2000;342:1560-7.

3 Abbas N, Lücking CB, Ricard S, et al. A wide variety of mutations in the parkin gene are responsible for autosomal recessive parkinsonism in Europe. Hum Mol Genet 1999;8:567-74.

4 Klein C, Pramstaller PP, Bernhard K. Parkin deletions in a family with adult-onset, tremor-dominant parkinsonism: expanding the phenotype. Ann Neurol 2000;48:65-71.

5 Muñoz E, Pastor P, Martí M, et al. A new mutation in the parkin gene in a patient with atypical autosomal recessive juvenile parkinsonism. Neurosci Lett 2000;289:66-8.

6 van de Warrenburg BPC, Lammens $M$, Lücking CB. Clinical and pathologic abnormalities in a family with parkinsonism and parkin gene mutations. Neurology 2001;56:555-7.

7 Hughes AJ, Daniel SE, Kilford L, et al. Accuracy of clinical diagnosis of idiopathic Parkinson's disease: a clinico-pathological study of 100 cases. J Neurol Neurosurg Psychiatry 1992;55:181-4

8 Lücking CB, Abbas N, Dürr A, et al. Homozygous deletions in parkin gene in European and North African families with autosomal recessive juvenile parkinsonism. Lancet 1998;352:1355-6.

9 Wang $M$, Hattori N, Matsumine H. Polymorphism in the parkin gene in sporadic Parkinson's disease. Ann Neurol 1999;45:655-8.

10 Hoenicka J, Vidal L, Morales B, et al. Molecular Screening in Spanish families with Parkinson's disease [abstract]. Mov Disord 2000; 15(suppl):200.

11 Periquet $M$, Lücking $C B$, Waughan JR. Origin of the mutations in the parkin gene in Europe: exon rearrangements are independent recurrent events, whereas point mutations may result from founder effects. Am J Hum Genet 2001;68:617-26.

12 Jordanova A, Kalaydjieva L, Savov A, et al. SSCP analysis: a blind sensitive trial. Hum Mutat 1997; 10:65-70.

13 Ellis LA, Taylor CF, Taylor GR. A comparison of fluorescent SSCP and denaturing HCPL for high throughput mutation scanning. Hum Mutat 2000;15:556-64. 